\title{
Genetic Damage and Cell Killing Induction by Five Head Lice Treatments on HaCaT Human Skin Cells
}

\author{
Abdullah M Alnuqaydan ${ }^{1}$ and Barbara J Sanderson ${ }^{2^{*}}$ \\ ${ }^{1}$ Medical Biotechnology, School of Medicine, Faculty of Medicine, Nursing and Health Sciences, Flinders University, Australia \\ ${ }^{2}$ Department of Medical Biotechnology, School of Medicine, Flinders University, GPO Box 2100, Adelaide, SA 5001, Australia
}

"Corresponding author: Sanderson BJ, Department of Medical Biotechnology, School of Medicine, Flinders University, GPO Box 2100, Adelaide, SA 5001, Australia, Tel: +61(08) 7221 8556; Fax: +61(08) 7221 8555; E-mail: Barbara.sanderson@flinders.edu.au

Received date: March 03, 2016, 2015; Accepted date: March 17, 2016; Published date: March 18, 2016

Copyright: (c) 2016 Alnuqaydan AM, et al. This is an open-access article distributed under the terms of the Creative Commons Attribution License, which permits unrestricted use, distribution, and reproduction in any medium, provided the original author and source are credited.

\begin{abstract}
Background: Chemical head lice treatments used by parents to treat head lice infestation in their children due to their rapid and reliable removal of head lice. However, those treatments can be absorbed through the skin. Children are more sensitive to absorbing chemicals than adults. We hypothesized that synthetic chemical-based head lice treatments cause cytotoxic and genotoxic damage to human skin cells in vitro.
\end{abstract}

Objective: To determine the cytotoxic and genotoxic damage of synthetic chemical-based head lice treatments on $\mathrm{HaCaT}$ human skin cells in vitro.

Methodology: Cytotoxicity measured by the methyl tetrazolium cytotoxicity (MTT) assay and the crystal violet assay. Also, the mechanism of cell killing was identified by the apoptosis detection, via Flow cytometry assay. The cytokinesis block micronucleus (CBMN) assay detected the frequency of binucleated cells (BN) with micronucleus $(\mathrm{MNi})$, to indicate genetic damage induced by head lice treatments.

Results: Tea Tree Oil (TTO), Pure Lavender oil and Pyrethrum did induce significant cytotoxicity. Also, they enhanced both early apoptosis and late apoptosis/necrosis. However, two head lice treatments, Permethrin (Lice Breaker) and Maldison (Malathion) (KP24) did not induce cytotoxicity. Early apoptosis and necrosis were observed in Permethrin treatment and late apoptosis and early necrosis were measured in Maldison (Malathion) (KP24). Moreover, Permethrin (Lice Breaker) and Maldison (Malathion) (KP24) induced micronuclei (MNi) at a frequency significantly higher (range $=15-25 \mathrm{MNi} / 1000$ binucleated cells, $n=3$ ) than the background frequency (media alone control; MNi range $=6 \mathrm{MNi} / 1000$ binucleated cells, $n=3$ ).

Conclusion: This study indicates that exposure to chemical based head lice treatments enhanced cell death by both early apoptosis and late apoptosis/necrosis also induced chromosomal damage in human skin cells.

Keywords Cytotoxicity; Genotoxicity; Cell culture; Head lice treatments; Cytokinesis-block micronucleus CBMN assay; Chromosomal damage

\section{Introduction}

Head lice infections in children, particularly those of primary school age, constitute an important public health issue. Reports and surveys on the infestation of head lice are present them as existing in epidemic proportions. It is common amongst children aged between 3 and 12 years old. The infestations of head lice are common in many countries. In Australia, for example a based survey of 25000 school children indicated that $48 \%$ (44/92) of long day care centres in region of Western Sydney reported head lice outbreaks [1] and $13 \%$ in Victoria and only $2 \%$ in Tasmania [2]. In Brazil, the prevalence of head lice varies between 30 to $45 \%$ and $14 \%$ in Chinese schools [3,4]. A lower infestation frequency of head lice is found in the United Kingdom with only $2 \%$ of children school being infected [5]. In the United States, infestation with head lice is most common in younger children in primary and elementary schools, there are up to 12 million infestations of head lice every year [6].
Chemical treatments are preferred by parents to treat their children due to their rapid removal of head lice. Head lice treatment based on pesticides can be absorbed through the human skin. Early exposure to pesticide can affect the neurodevelopment system of children from neonate to 7 years old [2,7-10]. Children are more sensitive to being affected and absorb a greater proportion of a given dose of chemical exposure than an adult $[10,11]$. Even a small pesticide dose can affect children's health and behaviour and influence their future development [11]. Pesticide exposure includes insecticides being correlated with a role in children's leukaemia [8]. Some head lice treatments are restricted due to their side effects. For instead, Malathion which is not recommended and is restricted in Canada, and Lindane which is banned in California [6,7]. DDT has been banned because it is toxic to people and persists in the environment $[11,12]$. Permethrin can cause eye and skin irritation despite being not very toxic to humans [13]. Malathion is available as a head lice treatment only by prescription after been taken off the market twice in the United States due to flammability and odours [14]. Pyrethrum (Pyrethrins plus Piperonyl Butoxide) is neurotoxic to lice but it can be absorbed through the gastrointestinal tract and pulmonary route [14]. 
Page 2 of 6

There are head lice treatment products that contain approximately $10 \%$ tree tea oil (melaleuca oil) and $1 \%$ lavender oil. Tea tree oil acts as a human poison if ingested and human poisoning cases were registered in 2003 by the American Association of Poison Control Centres [15]. A high concentration of TTO and lavender oil could result in skin irritations or burns $[15,16]$. Pyrethrins are neurotoxic to lice with reported low toxicity to mammalian cells. People who are sensitive to ragweed or chrysanthemums are, however, allergic to pyrethrins [6]. This study examines the cytotoxicity and genotoxicity of five currently used chemical based head lice treatments and their effects were monitored using an in vitro human skin cell model.

\section{Materials and Methods}

\section{Materials}

RPMI 1640 media and foetal bovine serum (FBS) were purchased from Gibco ${ }^{\circ}$ Cell Culture Media - Life Technologies (Australia). Cytochalasin B (Cyt-B) solution, Sodium dodecyl sulphate (SDS, approximately 99\%), Phosphate buffered saline (PBS) and 3-(4,5dimethylthiazol-2-yl)-2,5-diphenyltetrazolium bromide (MTT) were purchased from Sigma-Aldrich (USA). 96plate reader (BIO-TEK Instruments Inc., USA). Diff-Quik stains were purchased from Lab Aids (Australia). Cytospin centrifuge (Shandon, England). The Annexin V-FITC Apoptosis Detection Kit was purchased from BD Biosciences (Australia). TrypLE ${ }^{\mathrm{w}}$ was purchased from Life Technologies (Australia). All other reagents were obtained from sigma, unless otherwise stated.

\section{Head lice treatments}

There are three different groups of products currently used to treat head lice: Synthetic Pyrethroids such as Permethrin; Pyrethrins group, for example, Pyrethrum; Organophosphates such as Maldison; and herbal and essential oils such as Tea Tree Oil and lavender Oil. Any head lice treatment product released onto the Australian market must be registered with the Australian Register of Therapeutic Goods. Head lice treatments were obtained from a local chemist for which a prescription is not required. Head lice treatments examined in this study as following; Lice Breaker (Permethrin 1\% w/w), KP24 (Maldison $0.5 \mathrm{w} / \mathrm{w})$, Tea Tree Oil (100\% Pure), Lavender oil (100\% Pure) and Pyrethrum (4 g/L Pyrethrins plus 16 g/LPiperonyl Butoxide).

\section{Cell treatment}

The 96 well flat bottom were seeded with $10^{4}$ cells/well and incubated for $19 \mathrm{~h}$ to allow the adherence of cells at $37^{\circ} \mathrm{C}$ in $5 \% \mathrm{CO}_{2}$. The media were aspirated and replaced with $100 \mu \mathrm{l}$ of the treatment solution per well and were treated for $1 \mathrm{~h}$ prior to bioassays. Treatment solutions included serial dilutions of different head lice treatments. The negative or untreated control ( 0 dose) served as the media. The two doses of head lice treatments used in the CBMN assay (Table 1) were diluted from the commercial product to be at least two orders of magnitude lower in concentration. Therefore if the product is used as instructed (i.e., undiluted) to treat head lice, it will be at concentrations at the same order of magnitude or higher at which it is genotoxic and toxic in vitro. The choice of $1 \mathrm{~h}$ as duration of cell treatment is because of the treatment time that recommended for consumers to apply head lice treatment for at least 20 mins to $1 \mathrm{~h}$. If any head lice are found alive in the next morning then different head lice treatment should be used for more few hours to avoid the resistance of head lice (Table 1).

\begin{tabular}{|c|c|c|}
\hline Product & Dose $\times 10^{-4}(\mathrm{~V} / \mathrm{V})$ & $\begin{array}{l}\text { Code for table 2, figure } 4 \text { and } \\
\text { figure } 5\end{array}$ \\
\hline Control & 0 (zero) & 0 (zero) \\
\hline \multirow[b]{2}{*}{ Permethrin } & 100 & Low \\
\hline & 10 & High \\
\hline \multirow[b]{2}{*}{ Maldison } & 50 & Low \\
\hline & 5 & High \\
\hline \multirow[b]{2}{*}{ Tee Tree Oil } & 5 & Low \\
\hline & 1 & High \\
\hline \multirow[b]{2}{*}{ Lavender } & 10 & Low \\
\hline & 5 & High \\
\hline \multirow[b]{2}{*}{ Pyrethrum } & 50 & Low \\
\hline & 10 & High \\
\hline
\end{tabular}

Table 1: Doses of head lice treatments use in Flow cytometry and CBMN assay.

\section{Cell line and cell culture}

A human non-cancer keratinocytes cell line $\mathrm{HaCaT}$, were obtained from ATCC Cell Lines (USA). It was maintained in RPMI 1640 medium, with $10 \%$ fetal bovine serum (FBS) and $1 \%$ penicillin/ streptomycin (Thermo Scientific, Australia). Cells were seeded in tissue culture flasks and incubated at $37^{\circ} \mathrm{C}$ in a $5 \% \mathrm{CO}_{2}$ fully humidified incubator. HaCaT cells were subcultured when they reached $60-80 \%$ confluence.

\section{Methyl tetrazolium cytotoxicity assay}

The cytotoxicity of chemical head lice treatments was determined using the methyl tetrazolium cytotoxicity (MTT) assay as described in [17-20]. Cells were seeded at $10^{4}$ in a volume of $100 \mu$ into each well of a 96-well flat bottom plate. MTT solution with a final concentration 0.5 $\mathrm{mg} / \mathrm{ml}$ was added and then incubated for $4 \mathrm{~h}$ at $37^{\circ} \mathrm{C}$. After incubation, $80 \mu \mathrm{l} \mathrm{20 \%} \mathrm{SDS}$ in $0.02 \mathrm{M} \mathrm{HCl}$ was added. The plates were incubated overnight in the dark at room temperature. The absorbance (ODs) was measured on a spectrophotometric plate reader using a reference wavelength of $630 \mathrm{~nm}$ and a test wavelength of $570 \mathrm{~nm}$.

\section{Crystal violet assay}

The relative number of viable cells was determined using crystal violet assay $(\mathrm{CV})$ as described in [21]. Briefly, $50 \mu \mathrm{L}$ of crystal violet stain $(0.5 \%$ of crystal violet in $50 \%$ methanol) was added to each well and incubated for 10 minutes at ambient temperature. After 10 minutes, the plate was gently washed with distilled water then air dried. $50 \mu \mathrm{L}$ of $33 \%$ acetic acid was added to de-stain the cells. The absorbance (ODs) was measured on a spectrophotometric plate reader using a test wavelength of $570 \mathrm{~nm}$ with a reference wavelength of 630 . 


\section{Apoptosis assay via flow cytometry}

Annexin V-FITC apoptosis detection kit I (BD Biosciences, US) was carried out and measure by Flow cytometry. Following treatment, cells were washed twice in $0.1 \%$ sodium azide in PBS and then centrifuged at $78 \mathrm{~g}(1200 \mathrm{rpm})$ for $5 \mathrm{~min}$. The pellets were resuspended in $50 \mu \mathrm{l}$ binding buffer. Cells were double stained with $2.5 \mu \mathrm{l}$ of annexin VFITC and $2.5 \mu \mathrm{l}$ of PI. After $15 \mathrm{~min}$ of incubation in the dark at room temperature, $200 \mu \mathrm{l}$ of binding buffer was added to the mixture. The intensity of annexin V-FITC and PI was recorded by BD Accuri ${ }^{\mathrm{mm}}$ flow cytometry and analysed with BD CFlow Plus Software.

\section{Cytokinesis block micronucleus assay}

The mechanism of cell killing and genotoxicity of chemical head lice treatments was carried out using Cytokinesis Block Micronucleus Assay (CBMN) assay as described elsewhere [22,23]. Briefly, after treatment Cyt-B $(4.5 \mu \mathrm{g} / \mathrm{ml})$ was added to the media and the cultures were incubated at $37^{\circ} \mathrm{C}$ for $23 \mathrm{~h}$. Cells were trypsinized (TrypLE ${ }^{\text {rin }}$ Express Enzyme (1X), phenol red) and collected onto slides by a cytospin centrifuging for 5 minutes at 47 xg (@6000 rpm). Slides were air-dried, fixed by DiffQuick Fixative for $10 \mathrm{~min}$, and then double stained with stain 1 (red DiffQuick Stain) and then Stain 2 (blue DiffQuick Stain). Slides were scored as described in another study [24]. The chromosomal damage induced by treatment and total number of micronuclei $(\mathrm{MNi})$ in binucleated (BN) cells totalled 1000 .

\section{Data analysis}

Data are presented as the mean \pm SEM. The experiments were replicated at least three separate experiments Statistical analysis was carried out using ANOVA including Tukey's HSD post hoc test (version 22). The significance was determined at $\mathrm{P}$ value $<0.05$. Responses to treatment were compared to the untreated control ( 0 doses) which is represented as $100 \%$ survival.

\section{Results}

\section{Cytotoxicity effects of head lice treatments on HaCaT human skin cells}

The toxicity of head lice treatments on HaCat human skin cells in vitro was determined by incubating cells with treatments for $1 \mathrm{~h}$ (Figure 1). Two cytotoxicity assays were carried out to indicate the toxicity of the head lice treatments. The relative viability of cells was determined using the MTT cell survival assay. Relative cell number was measured using the crystal violet (CV) assay. Permethrin (Lice Breaker) and Maldison (KP24) showed no significant toxicity.

However, there was significant toxicity induced by the two highest doses $\left(100\right.$ and $\left.1000 \times 10^{-4} \mathrm{v} / \mathrm{v}\right)$ with Tea tree oil (TTO) and Pyrethrum treatments (Figures 2 and 3). Lavender Oil also induced significant level of toxicity but only at the highest dose $\left(1000 \times 10^{-4} \mathrm{v} / \mathrm{v}\right)$. The Nuclear division index (NDI) is a method used to measure the proliferative status of viable cells that can be used to assess general toxicity [22,25]. Figure 4 shows the results of NDI of head lice treatments compared to the untreated control.

The NDI values were: untreated control (0 dose) 1.66; Permethrin $\left(100 \times 10^{-4}(\mathrm{v} / \mathrm{v})\right) 1.46(P<0.05)$ and $\left(10 \times 10^{-4}(\mathrm{v} / \mathrm{v})\right) 1.37(P<0.01)$; Maldison $(50 \times 10-4(\mathrm{v} / \mathrm{v})) 1.52$ and $\left(5 \times 10^{-4}(\mathrm{v} / \mathrm{v})\right) 1.52$; TTO $\left(5 \times 10^{-4}\right.$ $(\mathrm{v} / \mathrm{v})) 1.46$ and $\left(1 \times 10^{-4}(\mathrm{v} / \mathrm{v})\right) 1.49$; Lavender Oil $\left(10 \times 10^{-4}(\mathrm{v} / \mathrm{v})\right) 1.54$ and $\left(5 \times 10^{-4}(\mathrm{v} / \mathrm{v})\right) 1.54(P<0.05)$; and Pyrethrum (Pyrethrins plus
Piperonyl Butoxide) $\left(50 \times 10^{-4}(\mathrm{v} / \mathrm{v})\right) 1.53$ and $\left(10 \times 10^{-4}(\mathrm{v} / \mathrm{v})\right) 1.57$ (Figures 2 and 3).

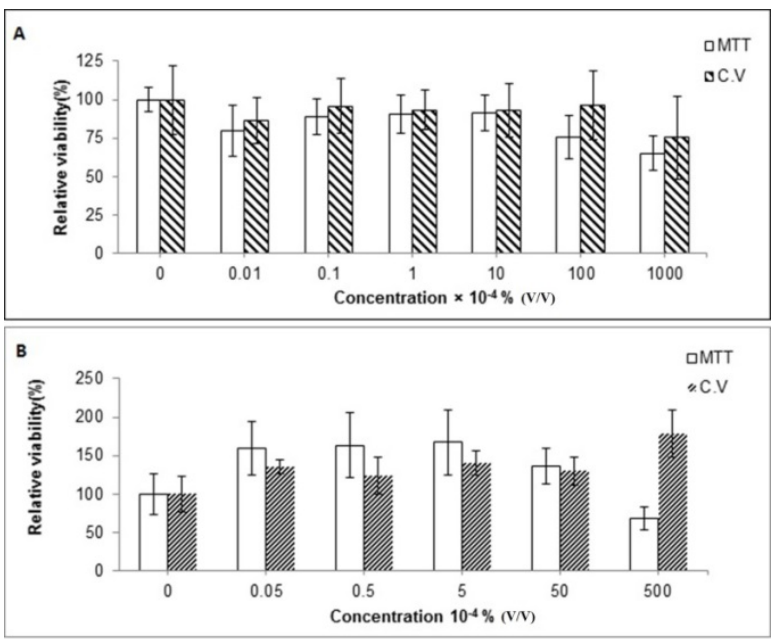

Figure 1: Survival relative to the untreated control, determined by the MTT assay. Relative cell number determined by Crystal Violet assay. Cells were plated in microplates at 10,000 cells/well then treated with (A) Permethrin $1 \% \mathrm{w} / \mathrm{w}$ and (B) Maldison $0.5 \mathrm{w} / \mathrm{w}$ for $1 \mathrm{~h}$. . Data are shown as percentage relative to untreated control and are mean of 3 replicates \pm S.E.M.
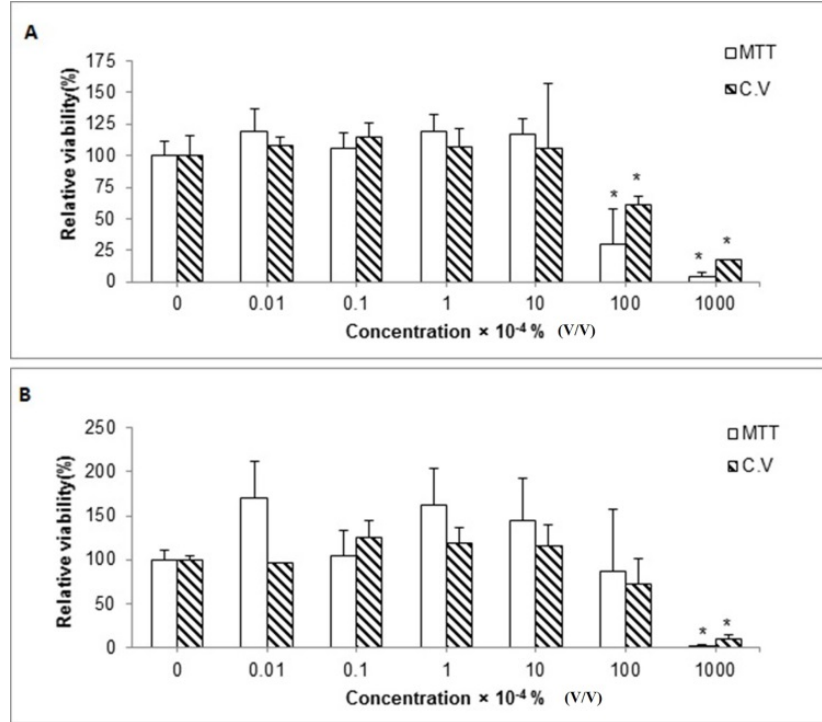

Figure 2: Survival relative to the untreated control, determined by the MTT assay. Relative cell number determined by Crystal Violet assay. Cells were plated in microplates at 10,000 cells/well then treated with (A) Pure Tea Tree Oil (TTO) $100 \%$ and (B) Pure Lavender Oil $100 \%$ for $1 \mathrm{~h}$. ${ }^{*}$ Significant difference at $\mathrm{P}<0.05$. Data are shown as percentage relative to untreated control and are mean of 3 replicates \pm S.E.M. 


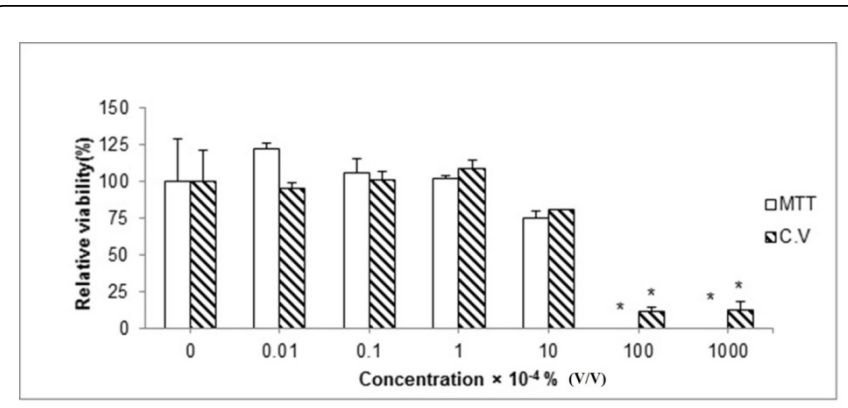

Figure 3: Survival relative to the untreated control, determined by the MTT assay. Relative cell number determined by Crystal Violet. Cells were plated in microplates at 10,000 cells/well then treated with Pyrethrum (4g/L Pyrethrins plus $16 \mathrm{~g} /$ LPiperonyl Butoxide) for $1 \mathrm{~h}$. ${ }^{\star}$ Significant difference at $\mathrm{P}<0.05$. Data are shown as percentage relative to untreated control and are mean of 3 replicates \pm S.E.M.

\section{Mechanism of cell killing}

The mechanism of cell death induced by head lice treatments for $\mathrm{HaCaT}$ cells for $1 \mathrm{~h}$ is shown in Table 2. Induced apoptosis and necrosis was determined by Cytokinesis-Block Micronucleus (CBMN) assay and Flow cytometry assay. A Flow cytometric assay was used to differentiate the live cells population, and early apoptotic and late apoptotic/necrotic cells population [26]. CBMN identified late apoptotic and early necrotic cells [22] (Table 2).

\begin{tabular}{|l|l|l|l|l|l|}
\hline & \multicolumn{3}{|l|}{ Apoptosis } & \multicolumn{2}{l|}{ Necrosis } \\
\hline \multirow{2}{*}{ Product } & Dose & CBMN & $\begin{array}{l}\text { Flow } \\
\text { cytometry }\end{array}$ & CBMN & $\begin{array}{l}\text { Flow } \\
\text { cytometry }\end{array}$ \\
\hline Control & 0 & $6.3 \pm 3.4$ & $1.2 \pm 0.3$ & $5.3 \pm 1.3$ & $1.7 \pm 0.8$ \\
\hline \multirow{2}{*}{ Permethrin } & Low & $25.3 \pm 3.4$ & $1.0 \pm 0.0$ & $40.6 \pm 14.31$ & $* 3.7 \pm 0.4$ \\
\cline { 2 - 6 } & High & $24.7 \pm 7.4$ & $* 3.6 \pm 0.0$ & ${ }^{*} 57.3 \pm 4.91$ & $* 5.4 \pm 0.6$ \\
\hline \multirow{3}{*}{ Maldison } & Low & $7 \pm 1.2$ & $1.1 \pm 0.4$ & $* 61.3 \pm 11.46$ & $0.9 \pm 0.3$ \\
\cline { 2 - 6 } & High & $* 27.6 \pm 3.2$ & $1.1 \pm 0.4$ & $32.6 \pm 4.25$ & $* 1.3 \pm 0.2$ \\
\hline \multirow{2}{*}{ Tee Tree Oil } & Low & $22 \pm 12.9$ & $1.3 \pm 0.2$ & $14.3 \pm 6.36$ & $1.4 \pm 0.1$ \\
\cline { 2 - 6 } & High & $23.6 \pm 9.6$ & $* 6.7 \pm 0.2$ & $15.3 \pm 2.96$ & $13.3 \pm 7$ \\
\hline \multirow{2}{*}{ Lavender Oil } & Low & $6.6 \pm 1.20$ & $* 5.6 \pm 1.2$ & $7.6 \pm 4.17$ & $6.7 \pm 1.7$ \\
\cline { 2 - 6 } & High & $6 \pm 3.21$ & $* 4.6 \pm 1.2$ & $4.3 \pm 1.76$ & $* 16.3 \pm 5$ \\
\hline \multirow{2}{*}{ Pyrethrum } & Low & $9.3 \pm 5.23$ & $1.4 \pm 0.6$ & $18 \pm 6.66$ & $2.3 \pm 0.3$ \\
\cline { 2 - 6 } & High & $9.6 \pm 5.24$ & $* 6.5 \pm 0.6$ & $11 \pm 1.52$ & $* 4.4 \pm 0.4$ \\
\hline
\end{tabular}

Table 2: Cell killing mechanism of head lice treatments determined by CBMN and the Flow cytometry based apoptosis/necrosis assay. Dose code from Table 1.

Significant difference at ${ }^{\star} \mathrm{P}<0.05$. Data are shown as the mean of three observations \pm SEM. For Flow cytometry $3 \times 10^{5}$ cells were scored for each treatment population analysed. In the CBMN assay, an average of 400 cells was scored.
CBMN results detected induction of a significant increase in late apoptosis induced only by a highest dose of Maldison $(0.5 \mathrm{w} / \mathrm{w})$. However, Flow cytometry results observed significant early apoptosis induced by high doses of Permethrin, TTO, Pyrethrum (Pyrethrins plus Piperonyl Butoxide) and both tested doses of Lavender oil. Significant necrosis was detected by the CBMN assay with a high dose of Permethrin and low dose of Maldison $0.5 \mathrm{w} / \mathrm{w}$. Flow cytometry indicated a significant necrosis was induced by the two doses of Permethrin and a high dose of Maldison $0.5 \mathrm{w} / \mathrm{w}$, lavender Oil and Pyrethrum (Pyrethrins plus Piperonyl Butoxide) (Figure 4).

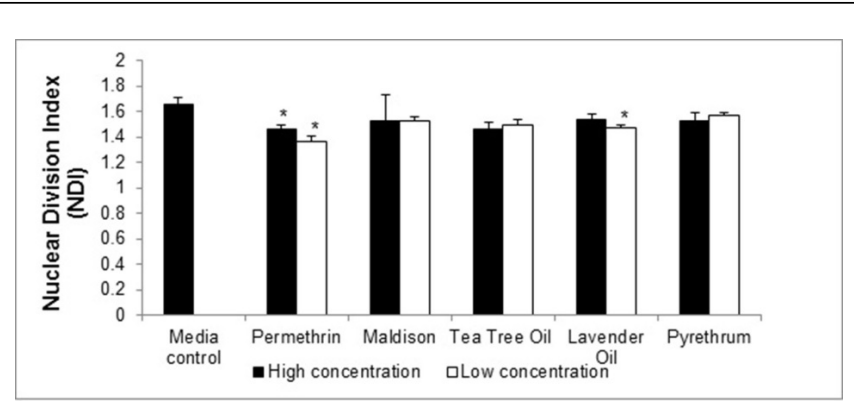

Figure 4: Nuclear Division Index (NDI) comparisons between untreated control (0 dose) and head lice treatments. HaCaT cells were plated described in materials and methods section. Cells received head lice treatments for $1 \mathrm{~h}$. (NDI) was determined by the cytokinesis Block micronucleus (CBMN) assay. Data are shown as percentage compared to untreated control and are mean of 3 replicates \pm S.E.M. Significant difference at ${ }^{\star} \mathrm{P}<0.05,{ }^{*} \mathrm{P}<0.01$. Dose code from Table 1.

\section{Genotoxicity of head lice treatments on HaCaT human skin cells}

The values of genotoxicity are given in Figure 5. Doses code from table 1. A significant increase in micronucleus (MNi) was observed in the high dose of Permethrin and both doses of Maldison (Figure 5).

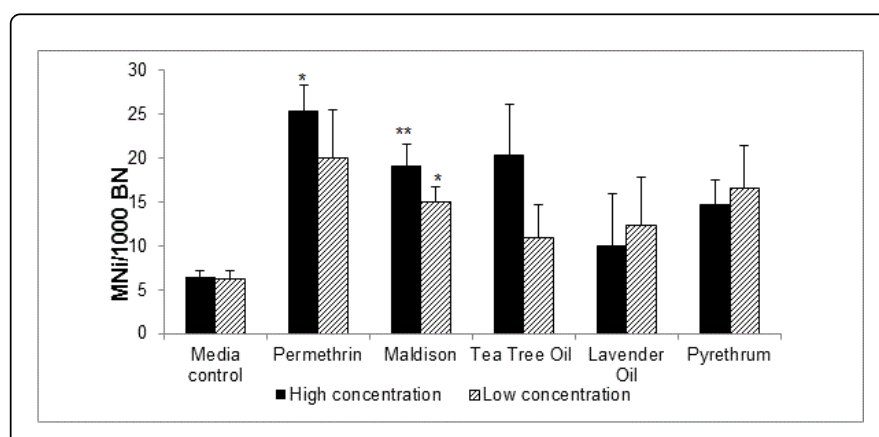

Figure 5: HaCaT cells were plated as described in the materials and methods section and head lice treatments for $1 \mathrm{~h}$. The frequency of micronuclei $(\mathrm{MNi})$ per 1000 binucleated cells was determined using the Cytokinesis Block Micronucleus (CBMN) assay as described in methods. Data shown as mean $\pm S E M ; n=3$. Dose code from Table 1 .

Other treatments showed an increase in the number of MNi but they did not reach significance. Nucleoplasmic bridge (NPB) and Nucleoplasmic buds (NBUDs) were not observed after HaCaT human 
skin cells were exposed to head lice treatment for $1 \mathrm{~h}$. NPB can be a rise from DNA misrepair of strand breaks in DNA that could lead to dicentric chromosome and NBUDs can be due to gene amplification [22].

\section{Discussion}

Children are the most sensitive sub-group in the population to the effect of chemical exposure, even for a small dose [10,11]. Head lice treatments examined in this study are common treatments after identification of head lice. Only a few studies are available for an analysis of the active ingredients of head lice treatments.

Permethrin (commercial concentration $1 \% \mathrm{w} / \mathrm{w}$ ) is reported to be the least toxic to humans although yet still show adverse effects, such as itching and superficial reddening of the skin [27]. Animal studies however, have demonstrated the toxicity of Permethrin in cats with clinical signs that appear within hours of exposure [28]. Current findings showed significant levels of cells in early apoptosis and in late apoptosis or necrosis following treatment of HaCaT human skin cells by Permethrin. The increase in these endpoints implies the induction of some level of cell death caused by Permethrin in this in vitro model. Necrotic cell death in vivo can be associated with inflammation and would link with the skin redness observed in some cases of the use of this product. In contrast, although there were decreases in viability in the two bioassays with increasing dose (Fig 1, A) these did not reach significance. One indicator of general toxicity is nuclear division index (NDI), a method for measuring the proliferative status of viable cells. Permethrin showed a significantly lower NDI value for $100 \times 10^{-4}(\mathrm{v} / \mathrm{v})$ dose; $1.46(P<0.05)$ and $10 \times 10^{-4}(\mathrm{v} / \mathrm{v})$ dose; $\left.1.37(P<0.01)\right)$ than the control (cells grown/treated with media). 1.0 is the lowest NDI value possible, and that can occur if all the viable cells have failed to divide during the period of the cytokinesis-block period of the assay [22]. Therefore, permethrin has had a broad toxic effect and dosedependently decreased the amount of division of the remaining viable cells after treatment. Permethrin also had a genotoxic effect, as it induced a significant increase in micronuclei (MNi) (Figure 5). $\mathrm{MNi}$ can arise from either complete chromosome loss or acentric chromosome fragments [22]. This type of genetic damage has been linked to carcinogenesis [22,25].

Maldison (Malathion) (Commercial concentration 0.5\% w/w), which has an organophosphate group, was restricted in the Unites States market in 1986 due to inflammation-related issues [27]. Also, because it is a cholinesterase inhibitor, there is a high risk of respiratory depression occurring in young children [27]. Despite these problems being identified, Maldison (Malathion) is still available for use. The current study indicated that Maldison (Malathion) induced significant early apoptosis and significant late apoptosis/necrosis, depending on the concentration and method used (Table 2). This induction of cell death, particularly necrosis, in treated populations would be consistent with the inflammation-related issues observed. In addition, to the potential hazard just discussed, Maldison induced genetic damage and induced significant increases in MNi compared to the untreated control and the levels increased with increasing concentration. This means that, as for Permethrin, exposure of the skin cells in the in vitro model results in significant risk of chromosomal damage. The changes in relative viability for Maldison did not follow any pattern related to concentration. At some concentrations the population expanded (showed increases in relative viability \%) and at others they were non-significantly killed (showed decreases in relative viability \%). This is hard to interpret and may be due to interaction of
Maldison with different aspects of metabolism at different concentrations. This is consistent result with in vivo study found that Malathion is genotoxic in mice [29]. In future studies it would be interesting to observe the cells microscopically for phenotypical changes and utilise a Live/Dead assay.

A previous study showed Tea Tree Oil (TTO) reduces the growth of human cells by $50 \%$ (IC50) compared to the control after one day at a range of $20-2700 \mu \mathrm{g} / \mathrm{ml}$, and that TTO is not mutagenic based on the outcome of the bacterial reverse mutation assay [15]. In the present study, TTO showed significant toxicity measured by the MTT and crystal violet assays (Figure 2A). This is not unexpected, as the concentrations used included those including the lower dilutions in the natural based products used to treat head lice and some higher concentrations used in other products. Significant early apoptosis was induced on HaCaT human skin cells by TTO. However, there were no MNi observed following TTO, which means that TTO does not pose a genotoxicity risk.

Pure Lavender oil (100\%) induced significant toxicity when measured by MTT and crystal violet as shown in Figure 2B. It was significant only at the highest concentration, while at other concentrations the response of the treated populations varied, as it did with Maldison (see discussion above). It also showed significant induction of early apoptosis and necrosis (Table 2). An increase in $\mathrm{MNi}$ was observed with lavender oil as shown in Figure 5, although it failed to reach significance. It would be interesting in the future to study the aspect of the action of Lavender oil further using additional genotoxic endpoints, and extra replicates for the CBMN assay. Together these finding mean that Lavender Oil is toxic and acts via necrosis and apoptosis.

Pyrethrum is used as lice shampoo to treat children suffering from head lice. The National Pesticide Information Centre reported that children who used Pyrethrin-based lice shampoo experienced irritation, burns, scratches to the eye with blurred vision and tearing [30]. Also, other symptoms observed were asthma, wheeze, cough, and difficulty breathing [30]. This study examined Pyrethrum (Pyrethrins plus Piperonyl Butoxide). Significant toxicity was measured by MTT and crystal violet assays (Figure 3). The mechanism of this cell death was investigated via two assays. It was found; Pyrethrum induced significant early and late apoptosis on $\mathrm{HaCaT}$ cells when measured by CBMN and Flow cytometry assays. The induction of two different mechanisms could mean that not only is programmed cell death involved but necrosis, with the implications as discussed above. No significant $\mathrm{MNi}$ were observed in $\mathrm{HaCaT}$ cells after exposure to Pyrethrum for $1 \mathrm{~h}$. Therefore Pyrethrum is not assessed as a being a genetic hazard but as being a toxic hazard in the in vitro model used in the current study.

In summary, Pyrethrum (Pyrethrins plus Piperonyl Butoxide) induced the highest significant toxicity level measured by MTT with $100 \%$ of cells killed. TTO at head lice product concentration $10 \times 10^{-4}$ $(\mathrm{v} / \mathrm{v})$ created a significantly high toxicity level measured by MTT and led to $70 \%$ of cells being killed. Permethrin (Lice Breaker) caused survival to decline with $35 \%$ of cells killed and Maldison (KP24) induced $32 \%$ of killed cells. Lavender oil was only toxic at the highest dose, but at the concentration it is found at in the product for head lice treatment $\left(1 \times 10^{-4}(\mathrm{v} / \mathrm{v})\right)$ showed no toxicity in the human cell model. Permethrin (Lice Breaker) and Maldison (KP24) induced significant levels of chromosome damage on $\mathrm{HaCaT}$ cells at concentrations less than the commercial concentration. As a result, exposure to commercial mixtures of the head lice treatments induced both early 
apoptosis and late apoptosis/necrosis; and also induced chromosomal damage to human skin cells. The end-points used in this study are relevant to real life health problems. Cancers that were diagnosed with a high level of necrosis most often have a poor prognosis [31]. Also, necrosis damaged tissue through inflammation plays an important role in the expansion of oncogenesis and tumours [31]. Cancers develop as a result of genetic instability and many cancers can carry chromosome breakage or complete chromosome loss [32]. The products examined in this study were found to pose hazards related to these phenomena.

\section{Acknowledgment}

We thank the Ministry of Education, Saudi Arabia, for its partial support of this project.

\section{References}

1. Jorm L, Capon AG (1994) Communicable disease outbreaks in long day care centres in western Sydney: occurrence and risk factors. J Paediatr Child Health 30: 151-154.

2. Counahan M, Andrews R, Büttner P, Byrnes G, Speare R (2004) Head lice prevalence in primary schools in Victoria, Australia. J Paediatr Child Health 40: 616-619.

3. Heukelbach J, Wilcke T, Winter B, Feldmeier H (2005) Epidemiology and morbidity of scabies and pediculosis capitis in resource-poor communities in Brazil. Br J Dermatol 153: 150-156.

4. Fan CK, Liao CW, Wu MS, Hu NY, Su KE (2004) Prevalence of Pediculus capitis infestation among school children of Chinese refugees residing in mountanous areas of northern Thailand. Kaohsiung J Med Sci 20: 183-187.

5. Harris J, Crawshaw JG, Millership S (2003) Incidence and prevalence of head lice in a district health authority area. Commun Dis Public Health 6: 246-249.

6. Frankowski BL, Bocchini JA, HEALTH TCOS, DISEASES COI (2010) Clinical Report-Head Lice. Pediatrics 126.

7. [No authors listed] (2008) Head lice infestations: A clinical update. Paediatr Child Health 13: 692-704.

8. Menegaux F, Baruchel A, Bertrand Y, Lescoeur B, Leverger G, et al. (2006) Household exposure to pesticides and risk of childhood acute leukaemia. Occup Environ Med 63: 131-134.

9. Roberts JR, Karr CJ, Council On Environmental Health (2012) Pesticide exposure in children. Pediatrics 130: e1765-1788.

10. Landrigan PJ, Goldman LR (2011) Children's vulnerability to toxic chemicals: a challenge and opportunity to strengthen health and environmental policy. Health Aff (Millwood) 30: 842-850.

11. Gilbert SG (2004) A small dose of toxicology: The health effects of common chemicals. CRC Press.

12. Downs AM, Stafford KA, Coles GC (1999) Head lice: prevalence in schoolchildren and insecticide resistance. Parasitol Today 15: 1-4.

13. Diel F, Detscher M, Borck H, Schrimpf D, Diel E, et al. (1998) Effects of permethrin on human basophils and lymphocytes in vitro. Inflamm Res 47 Suppl 1: S11-12.
14. Devore CD, Schutze GE, Okamoto J, Allison M, Ancona R, et al. (2015) Head Lice. Pediatrics 135: e1355-e1365.

15. Hammer KA, Carson CF, Riley TV, Nielsen JB (2006) A review of the toxicity of Melaleuca alternifolia (tea tree) oil. Food Chem Toxicol 44: 616-625.

16. Bozhanov S, Karadjova I, Alexandrov S (2007) Determination of trace elements in the Lavender inflorescence (Lavandula angustifolia Mill.) Lavender oil system. Microchemical Journal 86: 119-123.

17. Alnuqaydan AM, Lenehan CE, Hughes RR, Sanderson BJ (2015) Extracts from Calendula officinalis Offer in Vitro Protection Against $\mathrm{H} 2 \mathrm{O} 2$ Induced Oxidative Stress Cell Killing of Human Skin Cells. Phytotherapy Research 29: 120-124.

18. Mosmann T (1983) Rapid colorimetric assay for cellular growth and survival: application to proliferation and cytotoxicity assays. Journal of Immunological Methods 65: 55-63.

19. Young FM, Phungtamdet W, Sanderson BJ (2005) Modification of MTT assay conditions to examine the cytotoxic effects of amitraz on the human lymphoblastoid cell line, WIL2NS. Toxicol In Vitro 19: 1051-1059.

20. van Meerloo J, Kaspers GL, Cloos J (2011) Cell Sensitivity Assays: The MTT Assay. In IA Cree ed Cancer Cell Culture. Humana Press.

21. Ramezanpour M, Burke da Silva K, Sanderson B (2012) Differential susceptibilities of human lung, breast and skin cancer cell lines to killing by five sea anemone venoms. Journal of Venomous Animals and Toxins including Tropical Diseases 18: 157-163.

22. Fenech M (2007) Cytokinesis-block micronucleus cytome assay. Nat Protoc 2: 1084-1104.

23. Wang JJ, Sanderson BJS, Wang H (2007) Cyto- and genotoxicity of ultrafine $\mathrm{TiO} 2$ particles in cultured human lymphoblastoid cells. Mutat Res 628: 99-106.

24. Fenech $M(2000)$ The in vitro micronucleus technique. Mutat Res 455: 81-95.

25. Ionescu ME, Ciocirlan M, Becheanu G, Nicolaie T, Ditescu C, et al (2011) Nuclear Division Index may Predict Neoplastic Colorectal Lesions. Maedica (Buchar) 6: 173-178.

26. Jia Z, Misra HP (2007) Exposure to mixtures of endosulfan and zineb induces apoptotic and necrotic cell death in SH-SY5Y neuroblastoma cells, in vitro. J Appl Toxicol 27: 434-446.

27. Frankowski BL, Bocchini JA Jr, Council on School Health and Committee on Infectious Diseases (2010) Head lice. Pediatrics 126: 392-403.

28. Dymond NL1, Swift IM (2008) Permethrin toxicity in cats: a retrospective study of 20 cases. Aust Vet J 86: 219-223.

29. Giri S, Prasad SB, Giri A, Sharma GD (2002) Genotoxic effects of malathion: an organophosphorus insecticide, using three mammalian bioassays in vivo. Mutation Research/Genetic Toxicology and Environmental Mutagenesis 514: 223-231.

30. Center NPI (2014) PYRETHRINS. In NPI Center ed US.

31. White E, Green DR, Letai AG (2015) 14 - Apoptosis, Necrosis, and Autophagy. In JMWGMHAIB Thompson ed The Molecular Basis of Cancer (Fourth Edition). Content Repository Only!, Philadelphia.

32. Lengauer C, Kinzler KW, Vogelstein B (1998) Genetic instabilities in human cancers. Nature 396: 643-649. 